\title{
Los trasfondos económicos de un cambio jurisdiccional en Centroamérica. El caso del Partido de Nicoya
}

Les raisons économiques et politiques d'une transformation juridictionelle en Amérique Centrale. Le cas du Partido de Nicoya

The economic and political background of a jurisdictional change in Central America. The case of the Nicoya Party

José Antonio Fernández Molina

\section{OpenEdition}

Journals

Edición electrónica

URL: http://journals.openedition.org/bifea/9382

DOI: $10.4000 /$ bifea.9382

ISSN: 2076-5827

Editor

Institut Français d'Études Andines

Edición impresa

Fecha de publicación: 8 abril 2018

Paginación: 57-75

ISSN: 0303-7495

Referencia electrónica

José Antonio Fernández Molina, « Los trasfondos económicos de un cambio jurisdiccional en Centroamérica. El caso del Partido de Nicoya », Bulletin de l'Institut français d'études andines [En línea], 47 (1) | 2018, Publicado el 08 abril 2018, consultado el 06 noviembre 2020. URL : http:// journals.openedition.org/bifea/9382 ; DOI : https://doi.org/10.4000/bifea.9382

\section{(2) $(0 \Theta \Theta$}

Les contenus du Bulletin de l'Institut français d'études andines sont mis à disposition selon les termes de la licence Creative Commons Attribution - Pas d'Utilisation Commerciale - Pas de Modification 4.0 International. 


\title{
Los trasfondos económicos y políticos de un cambio jurisdiccional en Centroamérica. El caso del Partido de Nicoya
}

\author{
José Antonio Fernández Molina*
}

\begin{abstract}
Resumen
El cambio jurisdiccional más importante en la República Federal de Centroamérica (1824-1838) fue la segregación del Partido de Nicoya, el distrito nicaragüense meridional, para adscribirlo a Costa Rica, entonces limitada a la Meseta Central intermontana. Este artículo supera las explicaciones nacionalistas del relato oficial para explorar cómo los cambios en las coyunturas económicas y las dinámicas políticas a diferentes niveles — local, estatal, federal— explican el cambio de jurisdicción y su permanencia.
\end{abstract}

Palabras clave: mercado, formación del Estado, Nicoya, Costa Rica, Nicaragua, República Federal de Centroamérica

\section{Les raisons économiques et politiques d'une transformation juridictionelle en Amérique Centrale. Le cas du Partido de Nicoya}

\section{Résumé}

La modification de délimitation la plus importante en République Fédérale d'Amérique Centrale (1824-1838) a été le rattachement du Partido de Nicoya, le district nicaraguayen méridional, au Costa Rica qui était jusqu'alors circonscrit au territoire intra-montagneux de son plateau central. Cet article va au-delà des raisons nationalistes du récit officiel et montre comment les changements économiques et politiques survenus à différents niveaux — local, national et fédéral — expliquent cette modification et sa permanence dans le temps.

Mots-clés : marché, formation de l'État, Nicoya, Costa Rica, Nicaragua, Republique Fédérale ds Amérique centrale

\footnotetext{
* Catedrático jubilado, Universidad Nacional de Costa Rica. Correo electrónico: chepestar@gmail.com
} 


\title{
The economic and political background of a jurisdictional change in Central America. The case of the Nicoya Party
}

\begin{abstract}
No jurisdictional change in the configuration of the states that formed the Federal Republic of Central America (1824-1838) stands out as much as the segregation of the Nicoya Party in the southern Nicaraguan district in order to attach it to Costa Rica, which was limited at the time to the Central Plateau area. This article goes beyond the nationalist accounts characteristic of the official discourse to explore how changes in economic conditions and political dynamics at different levels (local, state, federal) explain the jurisdictional change and its permanence.
\end{abstract}

Keywords: market, state formation, Nicoya, Costa Rica, Nicaragua, Federal Republic of Central America

\section{INTRODUCCIÓN}

Pocos elementos son tan caros a la ideología costarricense como la «anexión» del Partido de Nicoya, supuestamente un proceso voluntario y unánime, parte del mito fundacional ordenado y pacífico. El libro conmemorativo de su centenario traslucía dinámicas sociales complejas, pues identificaba a «los ricos hacendados de Nicoya y Santa Cruz, y, en general, los hombres de orden», como responsables por reaccionar ante lo que pasaba en Nicaragua y acordar la adscripción a Costa Rica en reuniones privadas (Cabrera, 1924: 14). El lector entendía que los hombres de orden enfrentaron al desorden de Nicaragua, por usar el mismo lenguaje oblicuo ${ }^{1}$. Al carácter elitista de la solicitud de segregarse de Nicaragua para unirse a Costa Rica, a resolver por las autoridades federales sitas en Guatemala, el mismo libro añade la referencia a soldados, un elemento omitido en la historiografía costarricense.

Este artículo reinterpreta los contextos y los procesos que llevaron a la incorporación del Partido de Nicoya —identificado también como el Partido- a Costa Rica, a partir de nuevos datos y razonamientos explicativos. Siguiendo la lógica propuesta por Andrés Reséndez, este proceso se examina a partir de la interacción entre Estado y mercado (Reséndez, 2004: 4-5). La primera parte analiza las coyunturas económica y política en que tuvo lugar. Para ello discute la dinámica comercial de Nicoya con las provincias de Costa Rica y Nicaragua a finales del período colonial para determinar las cambiantes tendencias en el mercado. Igualmente contrasta la denominada «anarquía» nicaragüense con los proyectos económicos de las autoridades de Costa Rica. La segunda parte, si bien hace referencias a lo económico, se centra en el proceso político de segregación/adscripción. Este proceso fue complejo, con ritmos variables, en que los participantes actuaron en formas diversas y en que a la ley se unió la espada, pero esto solo es comprensible en el marco de los procesos descritos en la primera parte.

1 El autor está en deuda con los estudiosos del tema: Sibaja \& Zelaya Goodman (1974; 2015); Esgueva Gómez (2007); Buska (2006); Rodríguez (2012). La referencia a soldados está en Cabrera (1924: 398-399). 


\section{COYUNTURAS ECONÓMICAS Y DINÁMICAS POLÍTICAS}

A finales del siglo XVIII la zona añilera salvadoreña y el mercado de la ciudad de Guatemala eran el eje del mercado centroamericano, con el Partido especializado en productos pecuarios². La interrupción de las comunicaciones con los mercados europeos y la competencia del tinte hindú provocaron la crisis del añil centroamericano, reduciendo la demanda de queso y reses, como se puede ver en la figura 1. Las haciendas cayeron en un período de aislamiento del mercado, el mecanismo tradicional de supervivencia, pero buscaron nuevos mercados en el sur: un miembro de la élite llevó derivados pecuarios al Chocó en febrero de 18243.

El Partido dependía de Costa Rica para productos de primera necesidad. Los campesinos de la Meseta Central costarricense encontraron en el Pacífico centroamericano, incluida Nicoya, un mercado para sus excedentes. Entre 1769 y 1811 estos alimentos incluían papas, cebollas, ajos y conservas, que equivalían al 9,7\% del peso de los áridos (mercadería no líquida), ya que el grueso eran derivados de la caña de azúcar, susceptibles de convertir en aguardiente. Este intercambio fue afectado por las exigencias del Estado colonial, pues se contrajo entre 1786 y 1791 por la demanda de bestias de carga para transportar el tabaco del rey, como se aprecia en la figura 2.

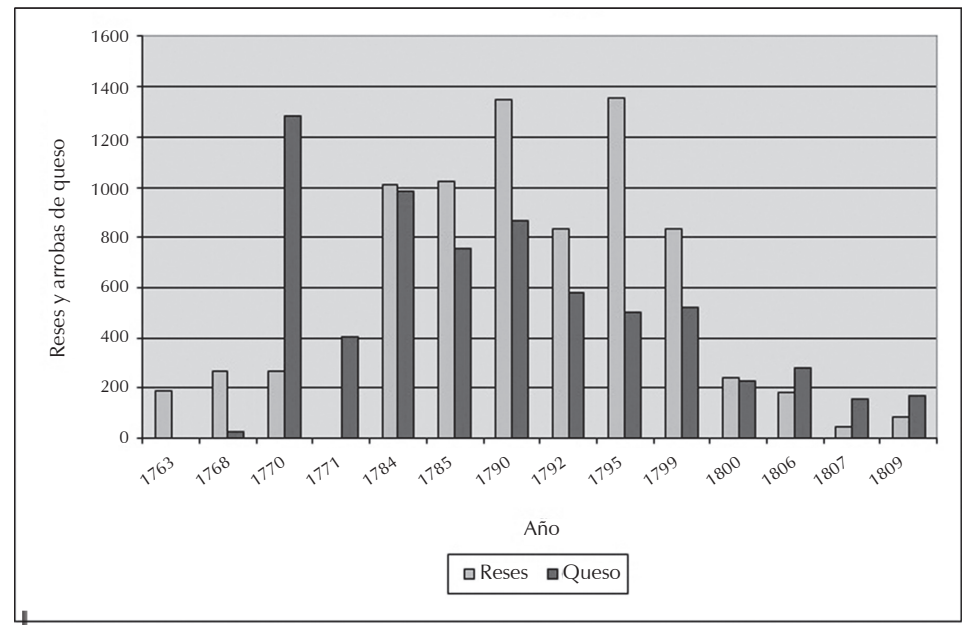

Figura 1 - Comercio de reses y queso de Nicoya a la provincia de Nicaragua, 1763-1809

Fuente: Archivo General de Centroamérica (en adelante AGCA) Signatura A1 (6) Legajo 77 Expediente 1081 (en adelante signatura, legajo y expediente serán separados por un guión); A1(6)-1-112; A3-2608-38541; A3(5)-1731237 y 1241; A3(5)-200-1431; A1(5)-12-1492; A1-78-1095; A1(5)-2471743; A1(6)-13-158; A3.5-154-7363; A1 (6)-15-179; A(6)-16-202; A3-3767809; A1(6)-18-230

2 Para un análisis de ese proceso véase Fernández Molina (1992; 2003).

3 Archivo Nacional de Costa Rica (en adelante ANCR) Provincial Independiente (en adelante PI) 1024. 
El proceso político no fue coherente con la pérdida de mercados en el norte, la parcial dependencia alimentaria de Costa Rica y los nuevos mercados. Las autoridades nicoyanas sentían animadversión por la dependencia en panela y tabaco de Costa Rica. En septiembre de 1822, ante una consulta sobre la decadencia económica, el cabildo nicoyano respondió desde su realidad de patria chica. Afirmó que obedecía a la exportación de dinero al extranjero, a los estancos

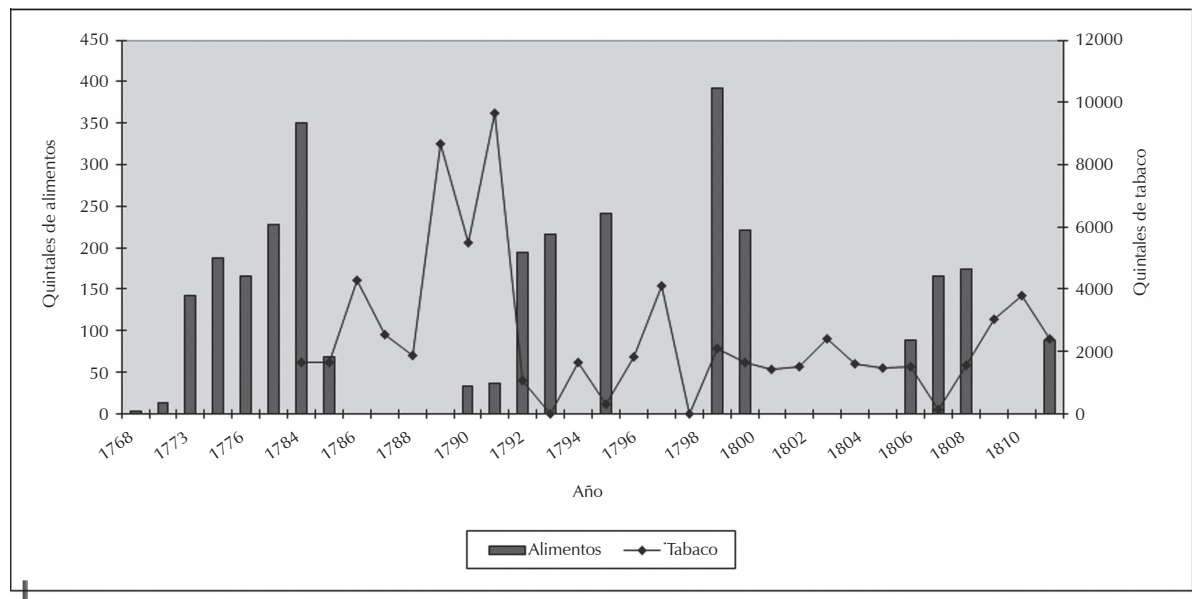

Figura 2 - Comercio de alimentos del Valle Central de Costa Rica a Nicoya (1768-1811) y de tabaco del rey a Centroamérica (1784-1811)

Fuentes: AGCA A1(6)-1-112; A3(5)-173-1241 y 1237; A1-310-6628; A3(5)-176-1266; A1(6)-10116; A1(6)-77-1088; A3(5)-200-1431; A3(5)-205-1479; A1(6)-13-157; A1(6)-78-1094; A1(6)78-1101 y 1100; A1-81-1137; A1(6)-13-158; A3-354-7364; A1(6)-15-176; A1(6)-16-204; A3375-7796; A1(6)-9-1119; A3-339-2275; Rico Aldave (2014: 97)

coloniales, pero «principalmente por tanto aguardiente que se ha introducido de Costa Rica»; por ello ordenó sacar todo el aguardiente de la jurisdicción. Además determinó que en la venta de panela regirían las leyes del mercado, pero si el mercante vendía durante cuatro días el precio era fijado por las autoridades. Finalmente, prohibió transportar aguardiente por mar y tasó a los comerciantes de panela con un real a partir del cuarto día de su estancia4 4 . Esta política se refinó en enero de 1823, cuando se impuso un real por carga de panela y dos reales por arroba de tabaco 5 .

La Junta de Legados de los ayuntamientos de Costa Rica invitó a Nicoya a formar parte del Estado en octubre de 1821, pero esta optó por Nicaragua (Iglesias, 1900: 2). Después de la independencia, como se puede apreciar en el cuadro 1, participó en los procesos electorales de aquel Estado.

La construcción del cuerpo político nicaragüense fue un proceso complejo y laborioso, Ileno de aristas sociales y entre localidades. Justin Wolfe ha argumentado

4 ANCR Municipal (en adelante M) 141, 10-10v.

5 ANCR M 82, 1-2v. 
Cuadro 1 - Vinculación del Partido de Nicoya con Nicaragua, 1822-1824

\begin{tabular}{|l|l|}
\hline 1822 & $\begin{array}{l}\text { Nombra diputado a Pedro Chamorro al Congreso Imperial por los partidos } \\
\text { de León, Segovia, Subtiava y Nicoya. }\end{array}$ \\
\hline 20-05-1823 & $\begin{array}{l}\text { Nombra elector de parroquia por Nicoya a Manuel Briceño, para votar en } \\
\text { las elecciones de partido en Villa de Nicaragua. }\end{array}$ \\
\hline 22-05-1823 & $\begin{array}{l}\text { Nombra elector de parroquia a Juan Felipe Gutiérrez y como suplente por } \\
\text { Santa Cruz a Saturnino Gutiérrez, para votar en las elecciones de partido } \\
\text { en Villa de Nicaragua }\end{array}$ \\
\hline $11-01-1824$ & $\begin{array}{l}\text { Nombra electores de parroquia por Nicoya a Antonio Briceño y Roque } \\
\text { Rosales, para votar en las elecciones de partido en Villa de Nicaragua. }\end{array}$ \\
\hline 1826 & $\begin{array}{l}\text { Nombra diputado en la Asamblea Constituyente de Nicaragua a Pedro } \\
\text { Muñoz. }\end{array}$ \\
\hline
\end{tabular}

Fuente: Avendaño (1995), 187; ANCR M 82, 12v-13; 13v-14; 18v-19v; Gobernación (en adelante G) 8445, 4-5; AGCA B-149-3210, 4-5v

que la llamada «anarquía» fue una creación de la historiografía de finales del siglo XIX, pero los documentos contemporáneos usaron ese apelativo para la conflictiva situación política (Wolfe, 2007: 34). En Nicaragua el término se encuentra en una correspondencia entre instancias locales de octubre de 18246, en documentos del cuerpo legislativo nicaragüense en abril de $1826^{7}$ y en una nota del ejecutivo reclamando los diezmos en marzo de 1836. En Costa Rica lo usó el Consejo en diciembre de 18349, y el ejecutivo en enero de 184910. A nivel local, el cabildo nicoyano lo utilizó en julio de 182611 y en marzo de 185412.

En este conflicto nicaraguense todas las facciones requerían ejércitos, alimentos y dinero. Se reintrodujeron cargas fiscales coloniales pues a finales de 1821 el alcalde de Nicoya quiso cobrar el tributo a los indios del Partido residentes en Costa Rica, a lo que se opusieron sus autoridades (Iglesias, 1900: 84). También la municipalidad nicoyana restableció el cobro de la alcabala en julio de 1823, pero restablecer este impuesto ad valorem no tenía sentido sin hacerlo en todo el istmo13. Además se exigieron préstamos forzosos al menos desde el primer semestre de 1824, pues el 1ํo de agosto de ese año en la Asamblea Constituyente se interpeló al Ejecutivo centroamericano — un triunvirato — sobre «las derramas y empréstitos forzosos hechos en León»14. El 15 de octubre de 1824 la Junta Superior Gubernativa de Managua solicitó a la Villa de Nicaragua que los hacendados nicoyanos aportaran ganados para defender «la más santa lucha». En fecha no

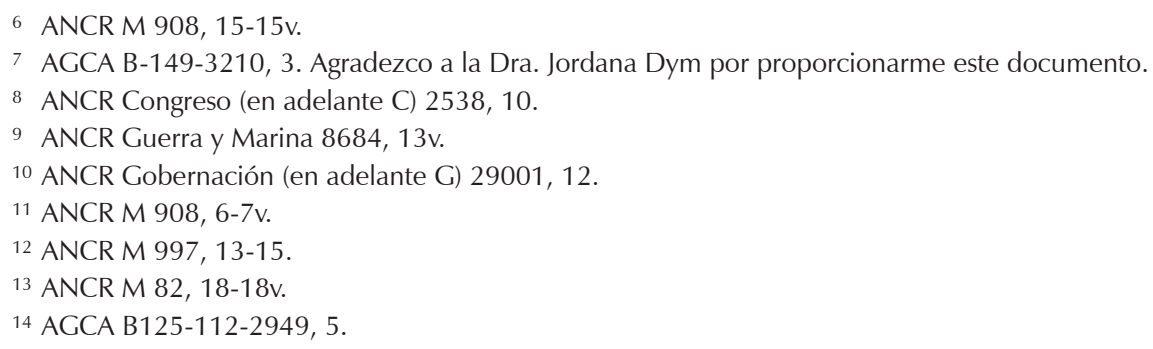


precisada el cabildo de Nicaragua invitó al de Nicoya a auxiliar los gastos bélicos. La respuesta se consideró «desagradable y ajena del estilo», por lo que el 27 de octubre de 1824 la planteó de nuevo15.

La política de las autoridades de Costa Rica respecto a Nicoya se definió a partir de las necesidades de construcción de un Estado viable según los criterios que justificaban el poder. La interdependencia entre Trono y Altar era clave y el nuevo Estado aspiró a coincidir con una diócesis, rompiendo con Nicaragua. En un informe del 17 de mayo de 1824, a sus diputados ante la Asamblea Constituyente sobre la invitación a Nicoya para adherirse, la Junta Superior Gubernativa argumentó que se le necesitaba para asegurar la congrua ${ }^{16}$. El nuevo Estado requería una base fiscal fundamentada en un proyecto productivo. El primer ciclo aurífero del Aguacate fue el primer intento por vincularse con el mercado mundial (Araya Pochet, 1976: 85-125). Para garantizar la extracción del oro la Junta Superior Gubernativa convirtió a las autoridades en agentes para reunir excedentes de carne y vegetales, intercambiables por azogue, armas y pólvora ${ }^{17}$. Dadas las dificultades para cumplir la contrata y el potencial de una ganadería nicoyana sin mercado, la agregación daría más base a ese intercambio, continuando la tendencia de un comercio volcado al Pacífico sur que se inició en 1811. Entre 1771 y 1800 el valor de las mercancías provenientes de Panamá fue inferior al $5 \%$ del total; en el período 1801-1810 aumentó al 11,6 \%, pero en el último decenio colonial alcanzó el 56,7 \% (Fernández Molina, 2003: 323).

Costa Rica evitó involucrarse en el conflicto nicaragüense. El Congreso Federal en diciembre de 1824 le ordenó auxiliar a Nicaragua con 2000 pesos en tropas o dinero ${ }^{18}$, pero antes de recibir esta ley la Constituyente rechazó enviar tropas, pues no se les franqueaba el paso por tierra o mar, se carecía de oficiales expertos y había atraso en la táctica militar19. El Estado costarricense en construcción, sin frontera sur colonizada, centró su atención en Nicoya, de donde llegaba constantemente información. En 1822 el jefe político de Bagaces reportó que allí residían indios del Partido, lo que sugiere que el golfo unía, más que separaba, la península del territorio continental (Iglesias, 1900: 84). En 1823 enfatizó la posibilidad de una invasión desde el norte y reportó el movimiento comercial. La continuidad del dominio nicaragüense sobre el Partido amenazaba a Puntarenas, el puerto costarricense en el Océano Pacífico ${ }^{20}$. Miembros de la élite arrendaron propiedades expropiadas por la Corona española en Bagaces (Gudmundson, 1978: 70): de haber anexado Nicaragua el golfo de Nicoya, habrían tenido el inconveniente que los nicaragüenses temieron posteriormente residir en un Estado y ser ganaderos en otro.

\footnotetext{
15 AGCA B125-112-2949, 14-15v.

16 ANCR PI 942, 3v-4.

17 Sesiones de la Junta Gubernativa de los 9, 10 y 16 de marzo, 2 de abril y 3 de junio de 1824 en Iglesias (1902: 250-251, 252-254, 260-261, 282-283).

18 AGCA B-113-2953, 14.

19 Orden sin número del 28 de diciembre de 1824, Costa Rica (1832: 67-68).

20 ANCR PI 751, 10-11, ANCR PI 668, 3-4v.
} 


\section{EL PROCESO POLÍTICO A NIVEL LOCAL, ESTATAL Y FEDERAL}

No fue sino hasta marzo de 1824 que, ante una invitación cuyo texto desconocemos, se inició el proceso que culminó en la agregación del Partido de Nicoya a Costa Rica. El 17 de mayo de 1824, el alcalde nicoyano acusó recibo e indicó que la sometería al cabildo abierto que se celebraba para la fiesta de Corpus Cristi21. El proceso dista de estar claro. La primera comunidad que optó por Costa Rica fue Santa Cruz; el 27 de junio de 1824 el vecindario delegó en su cabildo la resolución. Sin embargo, solo firmaron los ediles, sugiriendo que fue cabildo «abierto» solo de nombre, quizá para evitar oponerse al recién creado gobierno local22. Aparentemente ese mismo día el cabildo santacruceño solicitó la adscripción a Costa Rica, aunque el documento desapareció, como se verá. No hubo cabildo abierto el día de Corpus: no fue sino hasta el 4 de julio siguiente que la municipalidad de Nicoya con «algunos ciudadanos» rechazó la invitación, dejó abierta la posibilidad de que la Asamblea Nacional Constituyente resolviera un posible cambio jurisdiccional y agradeció el gesto23. El desacuerdo entre las dos comunidades no solo dividía a la península sino que aislaba a Nicoya de Nicaragua, a la que deseaba seguir perteneciendo.

En las siguientes semanas varios actores presionaron al cabildo, pues los firmantes del acta de adscripción de Nicoya a Costa Rica del 25 de julio son mucho más numerosos que en el documento anterior e incluía un representante de los indígenas (Esgueva Gómez, 2007: 110-111). Si bien la decisión sobre la segregación/agregación dependía del Congreso Federal, rindió frutos a corto plazo al aislar al Partido de la anarquía nicaragüense. El 8 de agosto de 1824 el cabildo santacruceño recibió una solicitud de armas, tropas y dinero de la Villa de Nicaragua; respondió que ya pertenecía a Costa Rica y que la petición debía elevarse a la capital para su resolución24.

La invitación costarricense triunfó en los dos pueblos más populosos de la península, pero no tuvo eco en el pueblo de Guanacaste, actual Liberia. Aunque el cabildo y los vecinos «de la mejor nota» vieron ventajas, la mayoría del vecindario se opuso en cabildo abierto celebrado el 23 de mayo de 1824, con tanta «tenacidad» que se temió por el orden público25. El 25 de agosto siguiente la corporación comunicó al gobierno de Costa Rica que había guardado silencio por si cambiaban los ánimos, pero quienes no habían asistido eran igualmente opuestos a segregarse de Nicaragua (Esgueva Gómez, 2007: 111-112).

La Junta Superior Gubernativa remitió las actas de agregación a las autoridades federales el 24 de septiembre de 1824, anunciando haber acogido bajo su protección provisional a pueblos «hermanos y huérfanos por la desorganización

\footnotetext{
21 ANCR PI 1026, 18.

22 ANCR G 8445, 8v-9v.

23 ANCR G 8445, 7v y 10-10v.

24 ANCR G 8445, 9-9v.

25 ANCR PI 973, 1-2.
} 
del estado de Nicaragua al que pertenecen por la ley». Justificó su invitación en la contradictoria situación del Partido, en lo gubernativo dependiente de León pero adscrito a Costa Rica en lo electoral, aunque evitó «una resolución perjudicial de alguna de las varias autoridades de Nicaragua», denunciando así la anarquía. La protección se limitaba a celar el orden, economía, quietud e instrucción de los pueblos del Partido, pero no le dio representación. Añadía que la posición, costumbres, relaciones comerciales y buena administración del Partido exigían «imperiosamente» separarlo de Nicaragua y agregarlo a Costa Rica; atribuyó a la distancia y al pésimo camino a León que no se hubiera jurado la Constitución Federal mientras en lo comercial exportaba por Puntarenas, que debía contribuir a defender. Reinterpretó la ambivalencia del pueblo de Guanacaste a la invitación, argumentando que deseaba la unión y, finalmente, indicó que los pueblos del litoral Pacífico no tenían la población para elegir diputado, lo que podrían hacer si Nicoya era añadida a Costa Rica... iproponían resolver la representación interna añadiendo territorio de otro estado26!

El Congreso Federal requirió año y medio para decidir, creando una situación anómala en que el Partido continuó bajo la jurisdicción de Nicaragua cuando ya había solicitado agregarse a Costa Rica. Las autoridades de esta última aprovecharon este impasse para crear una base legal para una ulterior acción. El 29 de enero de 1825, Juan Mora, primer jefe de Estado, pidió instrucciones al Congreso Constituyente costarricense que declaró que Nicoya y Santa Cruz debían considerarse interinamente agregados a Costa Rica hasta que las autoridades federales resolvieran la petición27. El 12 de marzo de 1825 el congreso costarricense autorizó la apertura de un camino al Lago de Nicaragua, con lo cual administraba en la práctica la jurisdicción28. Esa vía permitiría exportar carnes, untos, quesos, maderas y otros artículos por fomentar en los partidos de Nicoya y Bagaces29. Esta política era una variación de la seguida por la Junta Superior Gubernativa, redirigida hacia los mercados del Caribe.

La protección costarricense entró en contradicción con la obediencia al ejecutivo de Nicaragua y tener diputado ante la constituyente de ese Estado. Sin embargo, el 23 de agosto de 1824 la Junta Superior Gubernativa de Costa Rica nombró un comandante (Iglesias, 1902: 309-311). En nota fechada en León el 1o de julio del año siguiente, el gobierno de Nicaragua lo calificó de «comandante accidental». Con el argumento de haber cesado la anarquía y las convulsiones populares le pidió entregar el mando al designado, explicando a la tropa que habían cesado las causas de la separación ${ }^{30}$. El comandante enfrentó este intento de revertir la secesión por vía de obediencia militar, replicando el 25 de julio que

estos pueblos... vieron su antigua capital y demás lugares del estado, regidos unos por autoridades ilegales y por consiguiente reducido todo él a la

\footnotetext{
26 ANCR PI 1020, 5-7.

27 Acuerdo sin número del 29 de enero de 1825, Costa Rica (1832: 112).

28 Acuerdo sin número del 12 de marzo de 1825, Costa Rica (1832: 114-115).

29 ANCR C 138, 3.

30 ANCR Federal (en adelante F) 829, 2-2v.
} 
desastrosa anarquía y males que aún todavía se llora; Nicoya y Santa Cruz, viendo rotas las cadenas de la ley, las que les obligaban a la obediencia a las legítimas autoridades de su antigua matriz, creyeron por esto haber quedado aislados y en su primitiva libertad. Y para no tener parte en los desastres que se experimentaron, conociendo igualmente que es benéfico a los intereses y derechos de estos pueblos pertenecer al estado de Costa Rica.

Esperaba la resolución federal, pero para no romper puentes indicó que si el nuevo comandante se presentaba en la plaza «no rehusaré entregarle el mando pues soy el más amante de la paz y tranquilidad y ciega obediencia de la ley» 31 . La ambivalencia de la respuesta del comandante preocupó a Juan Mora, pues el 4 de octubre de 1825 su ministro comunicó al alcalde de Nicoya que no había descuidado la suerte de ese «benemérito» partido, escribiendo a todas las instancias federales 32 .

El interés se mantuvo en distintos grupos sociales. En diciembre de 1825 miembros de la élite dieron poder a un residente en Guatemala para representarlos ante las autoridades federales, con el fin de «conseguir la confirmación de su pronunciamiento por el estado de Costa Rica», gestión extemporánea pues el Congreso Federal aprobó la solicitud el 9 de diciembre anterior (Esgueva Gómez, 2007: 129-130). Los indígenas de Nicoya, a su vez, enviaron carta en enero de 1826 a la Asamblea costarricense solicitando su protección. Ya sabían que el jefe político nicaragüense pretendía cobrarles tributo y consultaban la legalidad de las cargas impuestas por el cabildo33.

El ritmo de los acontecimientos se aceleró en 1826, cuando el Senado Federal refrendó el 18 de marzo lo acordado por el Congreso y, al firmarlo el presidente Arce, se convirtió en ley34. Entre el 19 de abril — cuando se conoció el decreto en el pueblo de Guanacaste- y el 20 de octubre de 1826 — cuando todo el Partido quedó adherido a Costa Rica - la élite nicoyana revirtió por la fuerza dos rebeliones a favor de Nicaragua en barrios de Santa Cruz e impuso el decreto al pueblo de Guanacaste. Este proceso fue guiado por el Gobierno costarricense con una intervención militar sui generis.

El jefe político designado por Nicaragua para Nicoya arribó en abril, aunque ignoramos si conocía el decreto federal. El 19 de abril, el alcalde de Guanacaste comunicó a su homónimo de Santa Cruz la aprobación de la ley; apeló a la lealtad a Nicaragua del cabildo y la comunidad, inquiriendo si habría oposición «por los conductos y en la forma que corresponda». El pueblo de Guanacaste se reuniría el 21 de ese mes a deliberar sobre el decreto federal (Esgueva Gómez, 2007: 134). Ignoramos lo sucedido en Santa Cruz y lo acordado en Guanacaste, pero el 24 de abril el alcalde santacruceño comunicó el decreto al cabildo nicoyano, cuando estaba a punto de dar posesión al jefe político nicaragüense. Se suspendió

\footnotetext{
31 ANCR F 829, 3-3v.

32 ANCR PI 1303, 34v-35.

33 ANCR C 447.

34 ANCR F 15.
} 
la entrega del mando en espera del próximo correo y la confirmación transformó al alcalde Roque Rosales en Jefe Político en nombre del gobierno de Costa Rica 35 . Rosales informó a San José que Nicoya junto con Santa Cruz se declararon por Costa Rica, pero el influjo de Guanacaste hizo cambiar de opinión a algunos vecinos de esta última. El Gobierno costarricense le ordenó levantar sumaria y remitir a los facciosos, haciendo jurar la constitución del Estado en todos los pueblos con auxilio de tropas que permanecerían donde estimara conveniente.

Las instrucciones se ejecutaron en Santa Cruz, donde el 26 de abril Rosales comunicó el decreto, que fue obedecido por los munícipes y el síndico, pero la ausencia del alcalde reveló el conflicto que estalló después 36 . Hubo otra reunión el 11 de mayo presidida por Rosales con los vecinos principales que se pudo juntar y la milicia para leer el decreto. No tenían los originales de los documentos de 1824 en que se pronunciaron por Costa Rica pues el alcalde fugitivo se apoderó del archivo; sin embargo con base en copias, acordaron obedecerle. Reconocieron a las autoridades costarricenses, agradecieron a las autoridades federales y sustituyeron al alcalde rebelde (Esgueva Gómez, 2007: 136-137).

Un partidario de Nicaragua dejó reflejada su inconformidad en una carta a quien reconocía como comandante y jefe político «nombrado». En este documento, datado el 18 de mayo, expuso líricamente lo acaecido en Santa Cruz.

Penetrado del más vivo dolor, que me ocasiona ver a mis conciudadanos oprimidos y violentados del mando político del pueblo sobre no querer la adhesión al estado de Costa Rica, y querer éste por medio de la fuerza atraerlos a dicho Estado, como también por imponer a vuestra merced de los incidentes ocurridos sobre la materia, hago esta para que penetrado de las fatales consecuencias que pueden excitar unos trámites desconocidos, y autorizados por ellos mismos ordene lo que tenga por conveniente en semejantes $\operatorname{casos}^{37}$.

En su opinión el acta del 11 de mayo fue una imposición del alcalde nicoyano, irregular pues arribó con un grupo y utilizó al secretario de Nicoya, José Ángel Vidal, quien no era vecino. Denunció que no fue voluntad de los vecinos pues a pesar de haber sido convocados no apareció ninguno, por lo que tanto los santacruceños como los de Guanacaste esperaban la resolución del Congreso. La misiva develó claramente los motivos fiscales detrás del cambio jurisdiccional pues Vidal había usado la «intriga» — hoy diríamos retórica— para seducir al sencillo vecindario al clamar que el gobierno de León no era más que un «ladronisio» (sic), es decir un grupo de ladrones. Venía de allí y supo que impondría una contribución ad valorem a las propiedades, con lo que «acabarían con este partido».

Vidal preguntó a ocho vecinos si obedecían el decreto, a lo que contestaron que no eran ni la mitad de la manzana; hábilmente les replicó que quienes no comparecieron habían cedido su derecho. El informante denunció que, dados los

\footnotetext{
35 ANCR M 908, 4v-5.

36 ANCR M 908, 16-18.

37 AGCA B-149- 3210, 8-8v y 12-12v.
} 
castigos con que se amenazó a paisanos y militares, no se habían presentado por oponerse a Costa Rica, por lo que el acta era un engaño de Vidal al Estado de Costa Rica y a la Asamblea Federal Constituyente. Además firmó Roque Rosales seguido de los regidores y suboficiales. Para «abultar» añadió dos firmas de quienes no eran vecinos, poniendo en el cepo a los arrestados. La misiva concluía indicando que como comandante y jefe político proveyera los medios convenientes.

Las autoridades nicaragüenses enviaron un comisionado con una requisitoria «con el fin de contener a los opresores de nuestra patria», que entregó el 3 de junio en Nicoya solicitando recibo. Su petición fue recibida con mofa, en particular por Vidal, quien dijo «que para eso no se manchaba el papel de allí». El comisionado denunció que los vecinos andaban fugitivos, que ese día pasaron armados los munícipes de Nicoya hacia Playa Potrero a tomar declaración de los residentes. Finalmente manifestó al vicejefe José Miguel de la Cuadra que le informaba «para que dicte la providencia más oportuna a fin de libertar a un vecindario que sólo por sostener el gobierno de ese Estado se halla sufriendo tantos vejámenes y dura opresión»38. La carta fue interceptada pero su autor escapó a Nicaragua. El vicejefe nicaragüense protestó pues «no cesan las quejas de las autoridades de Santa Cruz y Guanacaste, por los insultos que sufren sólo por haber manifestado adhesión a este estado», por lo que solicitó la intervención del Gobierno costarricense (Esgueva Gómez, 2007: 134).

Ante la sorpresiva determinación federal, el Ejecutivo nicaragüense propuso una resolución que rechazó la Asamblea Constituyente, la cual nombró una comisión para redactar la revocatoria del decreto (Esgueva Gómez, 2007: 382-385). El 8 de abril de 1826 la comisión solicitó la revocatoria al Congreso Federal «porque así lo exigen los intereses del partido citado [Nicoya] y los de todo este infeliz estado». El documento negó que la solicitud hubiese sido reiterada o general, pues Guanacaste se había opuesto y Santa Cruz había dado instrucciones oponiéndose. Argumentó que los caminos con Nicaragua eran más transitables, que las riquezas del Partido se reducían al producto de haciendas de nicaragüenses que no podrían consumirse en Costa Rica por la mala comunicación y «la pobreza conocida de aquellos habitantes». Finalmente, señaló que el cambio de jurisdicción afectaría a los propietarios y al comercio de sus bienes. En la nota de remisión el vicejefe de la Cuadra enfatizó el arreglo de las milicias del Partido y el principio de autoridad que debía subordinar los pueblos a sus autoridades 39 .

El cabildo nicoyano tomó una actitud conciliadora con la comunidad opuesta al decreto. El 12 de mayo de 1826 escribió al cabildo de Guanacaste reconociendo la «discordia» respecto a su cumplimiento pero subrayando la «buena armonía» que siempre había existido entre las tres poblaciones. Añadía que se debía esperar la resolución a la apelación presentada por la asamblea nicaragüense, por lo que cabía no darle cumplimiento, y ofreció auxiliarla en lo que fuera posible dentro del orden legal40.

38 ANCR G 8957.

39 AGCA B-149-3210, 3-5v.

40 ANCR M, 5612, 6-7. 
El presidente de la República Federal, Manuel José Arce, envió copia del dictamen remitido por Cuadra a Mora Fernández el 26 de abril, solicitando un informe, previa consulta a los ayuntamientos del Partido41. El 28 de julio de 1826 el cabildo de Nicoya rechazó los argumentos nicaragüenses y en particular la defensa de los hacendados: si el comercio era libre con naciones extranjeras «¿cómo no lo ha de ser para unos pueblos hermanos?»42.

El siguiente día trajo una nueva crisis. Acaso porque la anexión fue decidida por los ediles sin participación popular o por diferencias significativas entre el centro y sus barrios, estos no aceptaron el decreto. Según Rosales las inquietudes se iniciaron con la visita del diputado a Guanacaste, pero recordó a las autoridades costarricenses que ya en 1823 los santacruceños se habían rebelado impunemente43. La víctima de la nueva rebelión fue José Ángel Vidal, instrumental en asegurar la aceptación del decreto. Rosales lo buscó para visitar Santa Cruz a entregar documentos relativos a la adscripción a Costa Rica, probablemente el informe solicitado por el presidente Arce. De acuerdo con Vidal, al saber que intentaban despojar al alcalde legítimo, convenció a Rosales de que se devolviera para no legitimar con su presencia ese acto o que lo vejaran. La «chusma... sin más autoridad que la del desorden y sin más ley que la arbitrariedad» intentó capturarlo; de haberlo logrado, pudo haber perdido la vida o verse obligado a defenderse, con la correspondiente efusión de sangre. Se refugió en la casa cural y escapó a la mañana siguiente 44.

La amenaza pesaba ahora sobre Nicoya. Rosales comunicó que el 29 de julio a las 9:30 pm había llegado un vecino de Santa Cruz a informar que el Barrio de la Costa en unión con algunos del barrio Puertadegolpe «tumultuariamente» tomaron el cabildo. Subrepticiamente los munícipes enviaron recado a Rosales informando «que la facción les mandaba firmaran un papel o informe intimidándoles que les quitarían la vida si no lo verifican». Como un funcionario colonial «responsable de la tranquilidad de los pueblos» y ante el peligro de un ataque por los facciosos se preparó para la defensa. En ausencia de comandante puso a cuatro soldados, un cabo y paisanos a vigilar las armas durante la noche y ordenó al tercenista de tabaco proveer los fondos para retribuir medio pre mientras recibía respuesta del Gobierno costarricense.

Si había colusión entre el diputado a la Constituyente, el cabildo de Guanacaste y los barrios rebeldes, la solución debía venir de las estructuras estatales costarricenses, por lo que ese mismo día Rosales envió dos correos a sus superiores. En el primero aseguraba que este nuevo atentado confirmaba las últimas declaraciones del sumario y la nota con que lo acompañaba, pues su causa fue un correo recibido de la Villa de Guanacaste con un pliego que llegó directamente a la casa del líder del tumulto. Aunque no lo expresó explícitamente, responsabilizaba a

\footnotetext{
41 AGCA B-149-3210, 2.

42 ANCR M 908, 6-7v.

43 ANCR G 8416, 81-82; G 8416, 79-80; M 5612, 8-9.

${ }_{44}$ ANCR M 5612, 8-9.
} 
Guanacaste por oponerse al decreto, por ello advirtió que de no tomarse medidas «se incrementará esta facción y tendría consecuencias dignas de llorarse»45. Con el segundo correo remitió las causas contra los líderes de las conmociones anteriores, informando que de las 26 armas solo funcionaban 5 o 6, con apenas 150 cartuchos. Señaló que 150 hombres bien armados y dirigidos pacificarían los barrios rebeldes 46 .

El informe puso en marcha los mecanismos del nuevo Estado. El 4 de agosto de 1826 el jefe de Estado Mora Fernández recibió los documentos sobre lo acaecido en Santa Cruz con una nota del Jefe Político Superior señalando que «ofrece soldados fieles, ha tomado medidas de seguridad, implora el socorro del gobierno para contener los males de la división y los efectos de las ambiciosas miras» de los opositores (Cabrera, 1924: 398-399). Al día siguiente ordenó remitir veinte fusiles al capitán Pedro Zamora47, quien debería traerlos de vuelta. Iría asociado del sargento primero veterano Pablo Godoy, pagado con fondos federales, para armar veinticinco milicianos retribuidos con medio pre que; con el jefe político subalterno, perseguirían y capturarían a quienes atentaran contra el orden 48.

Mora Fernández presentó la intervención como una acción de policía, sin mencionar el cambio de jurisdicción. Evitó enviar milicianos desde la Meseta Central porque quizá todavía temía algún conato de rebelión como el sucedido en Heredia contra el juramento a la constitución o la fallida intentona del español José Zamora ${ }^{49}$. Finalmente, la orden de traer de vuelta las armas muestra que no se veía en la adscripción un hecho definitivo: si se revocaba el decreto, Costa Rica no las perdería. En suma, el Estado costarricense intervino en un conflicto local... inclinando la balanza a su favor con una inversión mínima de recursos y sin añadir más tensiones en el interior. El armamento se envió a lomo de mula hasta Puntarenas a cargo de Godoy; desde allí armas y militares fueron transportados por el Golfo de Nicoya y Río Tempisque en busca del jefe político, como se puede ver en la figura 3.

El proceso político continuó en el Partido. El 10 de agosto, la municipalidad de Santa Cruz se reunió sin la presidencia de Rosales, rechazó los argumentos de la apelación nicaragüense y ratificó la agregación a Costa Rica (Esgueva Gómez, 2007: 138). Por estos días arribaron los oficiales con el armamento. El 16 de agosto de 1826 las autoridades políticas, militares y hacendarias de Santa Cruz y Nicoya juraron la constitución costarricense con tañido de campanas, pólvora, misas y vivas50. El 8 de setiembre, Zamora amenazó a quienes no habían jurado y señaló que deberían hacerlo el 17 de septiembre, so pena de «pasar con las bayonetas a toda costa, embargar sus bienes, quemar sus casas y traer a sus familias a morar a

\footnotetext{
45 ANCR G 8416, 81-82.

46 ANCR G 8416, 79-80.

47 Zamora era Capitán del Puerto de Puntarenas (Iglesias, 1902: 261-262).

48 ANCR Hacienda (en adelante H) 7288, 4-4v.

49 Decreto XXXVII del 15 de junio de 1825, Costa Rica (1832: 133-134); ANCR C 13606, 45-46v; Obregón (1981: 26-27).

50 ANCR M 908, 7v-8.
} 


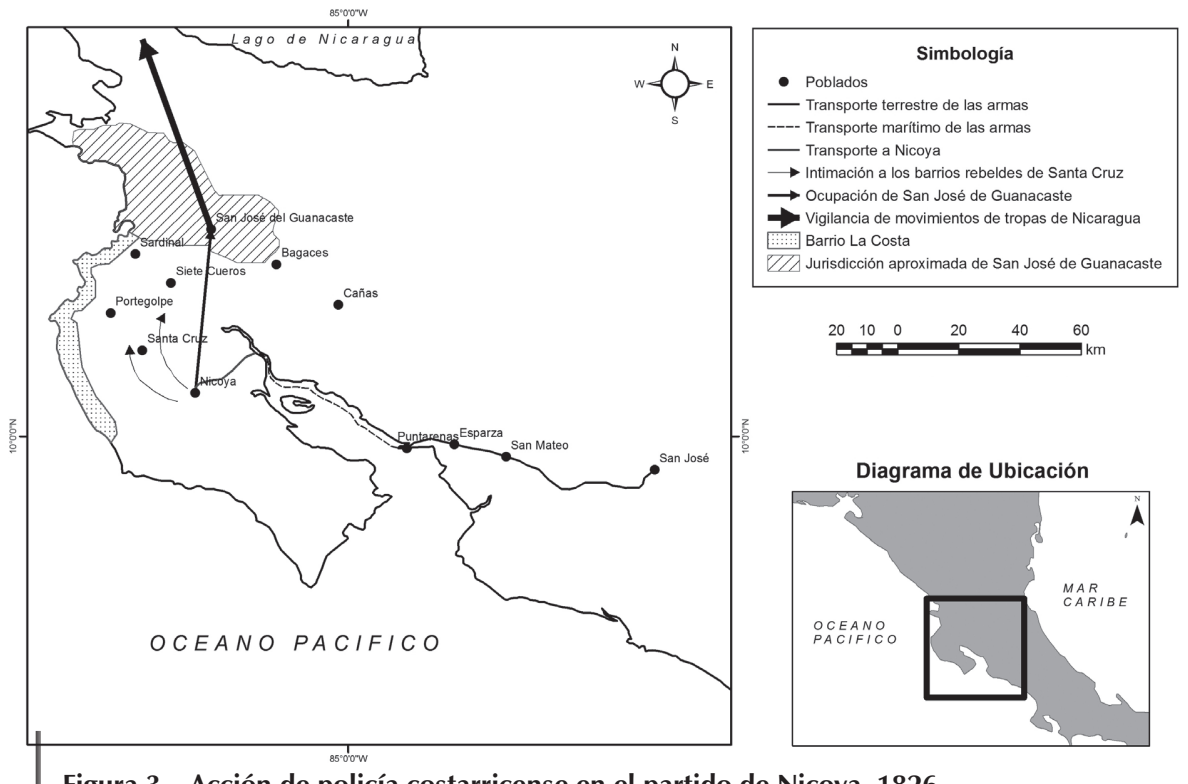

Figura 3 - Acción de policía costarricense en el partido de Nicoya, 1826

Fuente: reconstruido a partir de ANCR Hacienda-6557 y 7288, 4-4v, Federal-660, 1 y 2 , Municipal 908, 8v, Esgueva Gómez (2007: 139-140).

este pueblo [Nicoya]» (Esgueva Gómez, 2007: 139-140). La amenaza surtió efecto, pues ese día juraron los vecinos de la Costa y la Laguna ${ }^{51}$. Se iniciaron embargos para resarcir el costo de la expedición, pero el juzgado ordenó desembargar a cambio de fiadores; como aún no estaban firmes los embargos, los interesados continuaron en posesión de sus bienes 52 .

El gobierno costarricense remitió al federal los acuerdos municipales de Nicoya y Santa Cruz el 10 de septiembre siguiente. El presidente Arce recibió prueba de que «la mayoría» del Partido estaba a favor del decreto, pero el 7 de octubre pidió a Mora evitar una confrontación en las regiones limítrofes hasta la resolución del Congreso (Cabrera, 1924: 390). Para entonces en el Partido se daba una dinámica propia. Asegurada la lealtad de las poblaciones de la península, quedaba el problema del pueblo de Guanacaste. Según Rosales, la resistencia de Guanacaste y amenazas de la villa de Nicaragua presagiaban una invasión, dado que «es constante a la faz del universo los extravíos del orden del Estado de Nicaragua, porque si se han cometido y se cometen de atrás de mayor tamaño». Además el 4 de septiembre se le ordenó que hiciera jurar la constitución federal, que «escandalosamente» no se había hecho en dos años.

El jefe político subalterno propuso a Zamora forzar las juramentaciones en Guanacaste, pero este se negó por insuficiencia de tropas. Rosales entonces

\footnotetext{
51 ANCR M 908, f 8v

52 ANCR H 7288, 3-4.
} 
creó otro contingente - presumiblemente con las armas inservibles- con 18 hombres53. La ocupación comenzó el 24 de agosto, cuando Zamora pasó revista a 22 soldados, un tambor y al sargento primero en el pueblo de Guanacaste. Estos contingentes ocuparon la localidad hasta el 17 de octubre, 2117 días/soldado que se extendieron por 56 días. Debían identificar y neutralizar a los opositores a Costa Rica; «convencer» al cabildo de aceptar el decreto federal; enfrentar una posible invasión desde Nicaragua y hacer jurar las constituciones a autoridades, milicianos y pueblo.

Se priorizó neutralizar a los opositores, cuya identidad desconocemos. Dos baquianos montados los capturaron a las $11 \mathrm{pm}$ a legua y media del centro. Los reos fueron trasladados con escolta por cuatro bogas en un viaje de trece días hasta Puntarenas. Paralelamente se presionó al cabildo para que aceptara el decreto federal: un regidor y el procurador síndico cobraron luego por los días perdidos mientras duró la sesión. El documento aprobado el 24 de septiembre de 1826 reconoció la validez del decreto federal, pero no era una declaración por Costa Rica. El cura fue reacio a celebrar la misa pues ya había efectuado una el 15 de agosto. ¿El pueblo ya se había pronunciado — con juramento — por Nicaragua? ¿O había jurado esperar la nueva resolución del Congreso federal? Esto lo sugiere la presencia del funcionario nicaragüense a quien Nicoya rechazó, a cargo de la jefatura política y la comandancia, que entregó papeles y armamento54. El documento no rechazó los argumentos de Nicaragua. Por el contrario indicaba que el pueblo por

la fuerza con que viene la orden juraba, sin que se entienda por este juramento que ha sido su voluntad agregarse al Estado de Costa Rica, pues si se le deja obrar con libertad, ni ahora ni nunca, ni en tiempo alguno lo verificaría, respecto a serle gravosa la dicha agregación por todas las razones que tiene expuestas en el informe que se pidió por el Gobierno Federal, al del mismo Estado de que se trata, con previa audiencia de las municipalidades del partido55.

La presión militar solo obtuvo el reconocimiento del decreto y una jura condicionada de la constitución de Costa Rica, sin jurar la de la República Federal; la celebración fue un desfile del cabildo y vecindario con toques de caja. Posteriormente el tono del acta se atribuyó al secretario que la levantó, que para mediados de octubre andaba fugitivo ${ }^{56}$.

Rosales no consideró suficiente el acta, se trasladó a Guanacaste y convocó a la jura de ambas constituciones para el 8 de octubre; esta vez hubo víspera con sarao, música y aguardiente, en tanto que el día de las juras se dieron «aguas dulces» y licor. Por último, ante el rumor de una invasión desde Nicaragua, un jinete exploró el río Sapoá sin novedad. Su origen fue una iniciativa de las autoridades

\footnotetext{
53 ANCR G 8365, 1-1v.

54 ANCR G 8365, 1-1v.

55 ANCR G 8365, 2-3.

56 ANCR G 8365, 1-1v.
} 
de la Villa de Nicaragua vetada por el ejecutivo nicaragüense: desde el 19 de septiembre comunicó al de Costa Rica que impediría «los criminales designios del vecindario de Nicaragua» esperando la resolución del Congreso Federal (Cabrera, 1924: 387).

La población civil fue expoliada pues lo entregado a Zamora resultó insuficiente. Si la principal razón para el cambio jurisdiccional fueron los préstamos forzosos exigidos durante la «anarquía», esos mismos mecanismos se impusieron en nombre de Costa Rica. El 2 de octubre de 1826 se exigió a dos mujeres préstamos forzosos para socorrer a las tropas, amenazando con el rigor militar y garantizándolos con la Hacienda estatal 57 . Los vecinos de Nicoya y Santa Cruz aportaron 261 pesos, pero el pueblo de Guanacaste entregó 400 pesos como una «oferta voluntaria» para indemnizar los gastos de la tropa a cambio de mantener su cabildo58. No habían sido retribuidos para marzo de 1829 y no sabemos si los recuperaron 59.

Las reacciones en Nicaragua y Costa Rica fueron contrastantes. En octubre de 1826 el Ministro General de la primera comparó la actuación de Zamora con «aquellos medios de que usaron Cortés y Pizarro, ahora tres siglos, para encadenar nuestro continente», cuando la conquista se había vuelto odiosa (Cabrera, 1924: 388). Por otro lado, en vista de que el Partido había sido agregado «nuevamente» al Estado, el Congreso de Costa Rica le dio el derecho de participar en comicios federales y estatales60. Los principales actores fueron retribuidos políticamente. Pedro Zamora fue el primer representante del Partido en el congreso costarricense de 1826 a 1828: la élite local no tenía un compromiso mayor con otro habitante del interior (Obregón, 1995: 214-215). Por su parte José Ángel Vidal fue electo alcalde de Nicoya en 182761.

Las autoridades costarricenses evitaron imponer cargas fiscales que revirtieran el proceso. En el empréstito forzoso para adquirir el cuño se excluyó a Nicoya. El Ejecutivo lo justificó el 10 de marzo de 1827 en que «no lo juzga oportuno, ni político» pues «solo están agregados al Estado interinamente y aún para esto no faltaron sus divergencias y discusiones entre ellos... al estado interesa la prosperidad de la agregación de aquellos pueblos, no parece bien se les aleje y haga retrogradar gravándolos prematuramente» 62 . Una década más tarde, cuando se procedió a adjudicar el tabaco existente, el Estado no dudó en incluir a la élite local que hizo un pingüe negocio exportándolo a Nicaragua63.

Los ganadores de este proceso fueron los hacendados. Los terratenientes nicaragüenses descubrieron las ventajas de ser propietarios donde no existía la amenaza de los préstamos forzosos, lo que incentivó la llegada de coterráneos. Estos últimos y quienes se enriquecieron con el café adquirieron las tierras

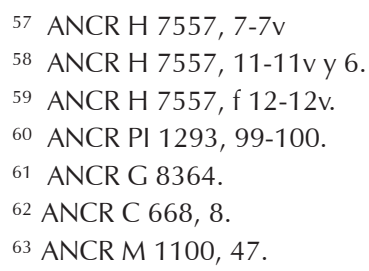


privatizadas de las cofradías y los baldíos (Gudmundson, 1978; Sequeira, 1985). El Estado retribuyó a quienes optaron por Costa Rica: el diputado del Partido ante la Constituyente de Nicaragua continuó a cargo del diezmo y eventualmente fue designado juez de primera instancia (Cabrera, 1924: 390)64. En 1827 el gobierno de Costa Rica calificó la guerra de Nicaragua como «intestina y anárquica», declarando su territorio asilo inviolable (Cabrera, 1924: 387, 391-393)65.

Las fuerzas del mercado consolidaron las medidas del Estado costarricense. El modelo agroexportador basado en el café creó un mercado para productos del norte. En 1850 entraron al Valle Central 4336 reses, el triple de las enviadas al norte de Centroamérica en el mejor año del período colonial 66 . No hay referencia al cacao nicaragüense durante la Colonia, pero se volvió común en la década de 1840: el vuelco hacia el Pacífico implicó abandonar los cacaotales del Caribe67.En contraste, la dependencia del algodón nicaragüense desapareció para 1844, fruto del ingreso de telas inglesas baratas68.

\section{CONCLUSIONES}

La interpretación de la segregación/adscripción debe superar el supuesto anacrónico de una confrontación entre dos Estados nación: la soberanía pertenecía entonces a la República Federal. En el contexto de los múltiples conflictos políticos que esta enfrentó, el cambio jurisdiccional de Nicoya fue de poca trascendencia... salvo para Nicaragua. Las reglas del juego institucionales estaban por definirse a todo nivel —ocal, estatal y federal-, a lo que la distancia y los problemas de comunicación añadieron malentendidos, contradicciones y rupturas entre las diversas instancias de poder. La élite costarricense se movió hábilmente en los pasillos del poder de la República Federal y, con un mínimo de inversión, sin batallas gracias a que Nicaragua respetó las mismas reglas, aumentó su territorio, aseguró su puerto en el Océano Pacífico y quedó en situación de reclamar participación en un posible canal interoceánico. La complejidad del proceso se olvidó porque la historia oficial se construyó después de 1850, requirió de pocas líneas y, aunque los ánimos se caldearon, no hubo efusión de sangre.

La caficultura potenció la economía costarricense desde la década de 1830, atrayendo ganado y cacao nicaragüense a un pujante mercado. Las plantaciones de banano, una nueva modalidad de vinculación con el mercado mundial, requirieron mano de obra nicaragüense: las fuerzas del mercado consolidaron la adscripción hecha por la ya difunta Federación.

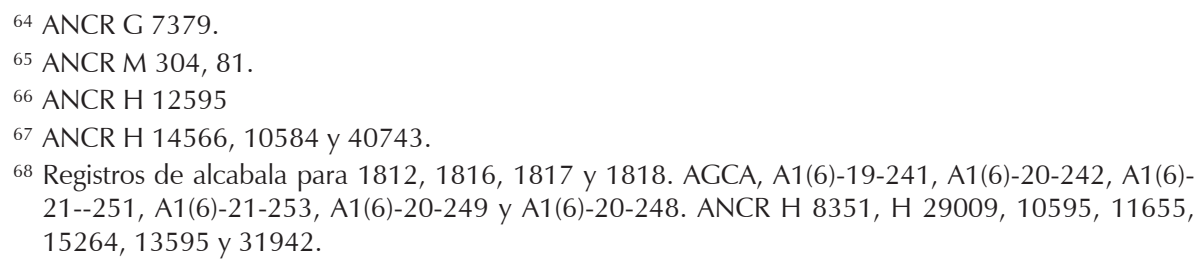




\section{Referencias citadas}

ARAYA POCHET, C., 1976 - La minería en Costa Rica: 1821-1843. Revista de Historia, 1 (2): 83-125.

AVENDAÑO, X., 1995 - Procesos electorales y clase política en la Federación de Centroamérica (1810-1840), 278 pp.; México: El Colegio de México. Tesis doctoral.

BUSKA, S. I., 2006 - "Marimba por tí me muero". Region and Nation in Costa Rica, 18241939, 257 pp.; Indiana: Tesis doctoral, Indiana University, Department of History.

CABRERA, V., 1924 - Guanacaste. Libro conmemorativo del Centenario de la incorporación del Partido de Nicoya a Costa Rica: 1824-1924, 486 pp.; San José: Imprenta María V. de Lines, Secretaría de Gobernación.

COSTA RICA, 1832 - Colección de los decretos y órdenes que ha expedido la Legislatura desde el día 6 del mes de septiembre de 1824 hasta el 29 de diciembre de 1826, xxxii + 341 pp.; San José: Imprentas de la Paz y la Libertad.

ESGUEVA GÓMEZ, A., 2007 - Las fronteras de Nicaragua y Costa Rica en los documentos históricos, 464 pp.; Managua: IHNCA-UCA.

FERNÁNDEZ MOLINA, J. A., 1992 - Producción indígena y mercado urbano a finales del período colonial. La provisión de alimentos a la ciudad de Guatemala. 1787- 1822. Revista de Historia, 26: 9-30.

FERNÁNDEZ MOLINA, J. A., 2003 - Pintando el mundo de azul. El auge añilero y el mercado centroamericano, 1750-1810, 367 pp.; San Salvador: CONCULTURA.

GUDMUNDSON, L., 1978 - La expropiación de los bienes de las obras pías en Costa Rica, 1805-1860: un capítulo en la consolidación económica de una élite nacional. Revista de Historia, 7: 37-92.

IGLESIAS, F. M., 1900 - Documentos relativos a la independencia. Actas de la Junta Gubernativa y del Primer Congreso Constituyente-25 de octubre de 1821 al 29 de marzo de 1823, Tomo II, 426 pp.; San José: Tipografía Nacional.

IGLESIAS, F. M., 1902 - Documentos relativos a la independencia. Actas de la Asamblea Provincial y de la Junta Gubernativa-1823 y 1824, Tomo III, 346 pp.; San José: Tipografía Nacional.

OBREGÓN, R., 1981 - Hechos militares y políticos, 419 pp.; Alajuela: Museo Histórico Cultural Juan Santamaría.

OBReGÓN, R., 1995 - El Poder legislativo en Costa Rica, 541 pp.; San José: Asamblea Legislativa, Sección de Publicaciones y Extensión Cultural, Biblioteca Monseñor Sanabria.

RESÉNDEZ, A., 2004 - Changing National Identities at the Frontier. Texas and New Mexico, 1800-1850, 309 pp.; Cambridge: Cambridge University Press.

RICO ALDAVE, J., 2014 - La Renta de Tabaco en Costa Rica (1766-1860), 564 pp.; San José: EUNED.

RODRÍGUEZ, A., 2012 - Una mirada microanalítica sobre la participación de la familia Briceño Viales en el proceso de anexión del Partido de Nicoya a Costa Rica. (17861824), 171 pp.; San José: Universidad de Costa Rica. Trabajo final de graduación aplicada, Maestría Profesional en Historia.

SEQUEIRA, W., 1985 - La hacienda ganadera en Guanacaste: Aspectos económicos y sociales 1850-1900, 220 pp.; San José: EUNED.

SIBAJA, L. F. \& ZELAYA GOODMAN, C., 1974 - La Anexión de Nicoya, 185 pp.; San José: Comision Nacional de Conmemoraciones Históricas. 
El Partido de Nicoya: trasfondos económicos y políticos de un cambio jurisdiccional en Centroamérica

SIBAJA, L. F. \& ZELAYA GOODMAN, C., 2015 - Nicoya. Su pasado colonial y su anexión o agregación a Costa Rica, ix + 365 pp.; San José: EUNED.

WOLFE, J., 2007 - The Everyday Nation-State. Community and Ethnicity in NineteenthCentury Nicaragua, 288 pp.; Lincoln: University of Nebraska Press. 